\title{
NASA's S’COOL Project \\ Bridging the Divide Between the 'Real' World and the Classroom
}

\author{
Roberto Sepulveda \\ Scientific Applications International Corporation \\ Hampton, VA, USA \\ R.Sepulveda@larc.nasa.gov
}

\author{
Dr. Lin H. Chambers \\ Atmospheric Sciences \\ NASA Langley Research Center \\ Hampton, VA, USA \\ Lin.H.Chambers@nasa.gov
}

\begin{abstract}
In an effort to bridge the gap between scientific research, teacher instruction and student learning, the CERES Students' Cloud Observations On-Line (S'COOL) Project offers a unique perspective on how to narrow the divide between the 'real' world and the classroom. Realitybased learning has become a staple in the education of our youth and the S'COOL Project has taken this concept one step further.
\end{abstract}

Keywords-reality-based learning. Science in the classroom.

\section{INTRODUCTION}

The S'COOL Project [1] is the principal educational outreach initiative of the Clouds and the Earth's Radiant Energy System (CERES) program [5], part of NASA's Earth Observing System. S'COOL was conceived in late 1996 prior to the successful launch of the first CERES instrument aboard the TRMM satellite in November 1997. As part of the validation activity for CERES, S'COOL engages K-12 students in making observations of the sky at the time a CERES instrument passes over their location. These observations are used as one element of an extensive effort to validate the CERES cloud mask and cloud property retrievals. Four additional CERES instruments have since been launched, two each on the Terra and Aqua satellites.

S'COOL addresses NASA's goal to "inspire and motivate students to pursue careers in science, technology, engineering and mathematics" [3]. It provides a simple and effective means for educators to bring authentic science into their teaching practice. By actively involving students in the process of data acquisition, geosciences and remote sensing come to life for inquisitive minds. There are currently S'COOL participants in all 50 US states and more than 60 other countries, and to date they have reported more than 33,000 observations of cloud conditions (Fig.1). These observations are available via the Internet (http://scool.larc.nasa.gov) for analysis by S'COOL participants

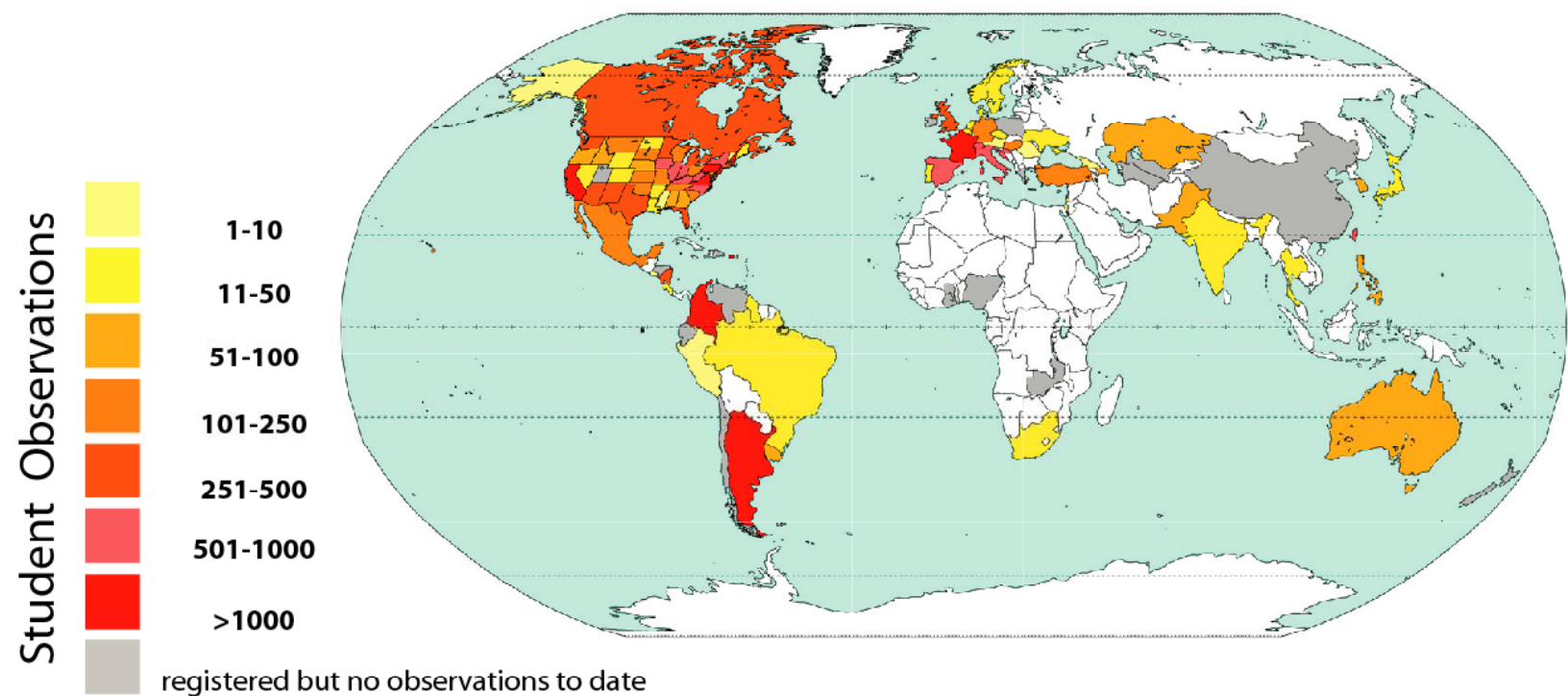

Fig. 1. Student observation counts by country (and states in the US) showing the global appeal of the CERES S'COOL project. 


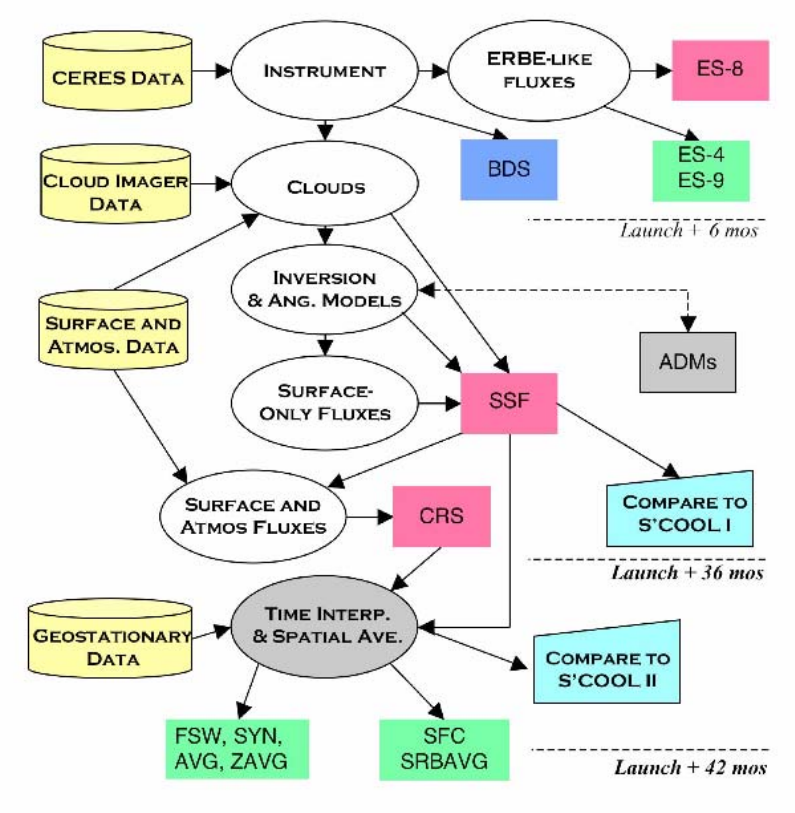

Fig. 2 CERES Data Flow Diagram

\section{SCIENCE-DRIVEN FOCUS}

The S'COOL Project has evolved over its eight years of existence as the CERES team has progressed in producing and analyzing the various CERES data products. More than just an instrument, the CERES program is a highly integrated effort to combine data from up to 11 remote sensing instruments on 7 different spacecraft, along with a broad range of ancillary data, to produce climate-quality data records that enable study of long-term change in the Earth's radiation budget. Production of CERES data products was planned to proceed in a phased manner, where newer and more sophisticated data products depend on the results from earlier products (see the data flow diagram, Fig. 2). For the first several years, validation efforts focused on the Single Satellite Footprint (SSF) data product, which provides cloud mask and cloud property data for individual CERES instrument fields of view. More recently, validation efforts have shifted to the Time Interpolation and Spatial Averaging (TISA) data products, which utilize geostationary data from a number of satellite platforms to correctly account for the diurnal cycle in the radiation budget, and thus produce highly accurate monthly mean products.

This shift in focus has lead to one recent and major change in the S'COOL project: in addition to cloud observation reports timed to CERES overpasses, we now also solicit observations corresponding to the 3-hourly geostationary data that TISA uses. This change was announced along with material that further explains, for a K-12 audience, how the science focus of CERES is progressing. To allow S'COOL participants to determine the appropriate observation times for their location, a clickable map has been added to the website that provides geostationary observation times on a 10 degree grid (Fig. 3).
This development also has the benefit of addressing a common obstacle reported by educators trying to implement S'COOL in the classroom: the varying times of daily Terra, Aqua (and TRMM) overpasses make it a challenge to integrate S'COOL into some academic schedules.

Validation of the CERES cloud products has also progressed since CERES began. Comparison to a variety of satellite and ground-based reference data has already lead to significant improvements in the algorithms for the cloud mask and retrieved cloud properties [2]. Recent assessments indicate that the areas where the greatest challenges remain are in the Earth's polar regions (north and south of 60 degrees latitude) [4]. These areas remain challenging due to the prevalence of bright surfaces - snow and ice - that confound many cloud retrieval methods; and long periods of darkness during polar night and polar twilight that eliminate information from shortwave imager channels. The former presents no challenge to surface observers, who can easily distinguish between snow and ice on the ground and clouds aloft. The latter presents some impediment to surface observers, but under some low lighting conditions cloud observations - at least the presence or absence of clouds - are still possible.

To assist in validation of polar cloud retrievals, S'COOL's recent outreach and recruitment efforts have been focusing more directly on high latitude locations, such as Alaska, northern Canada, and Scandinavia (although observations in other areas continue to be of interest, as the CERES team begins examining measurements sorted by different cloud types). While these high latitude areas are not visible to the geostationary satellites, they have multiple CERES overpasses each day due to the fact that the Terra and Aqua spacecraft are in polar orbits, and thus observe most of the polar regions every 90 minutes or so. Interested teachers in these areas should therefore have lots of schedule flexibility in implementing S'COOL.

\section{SCIENCE IN THE CLASSROOM}

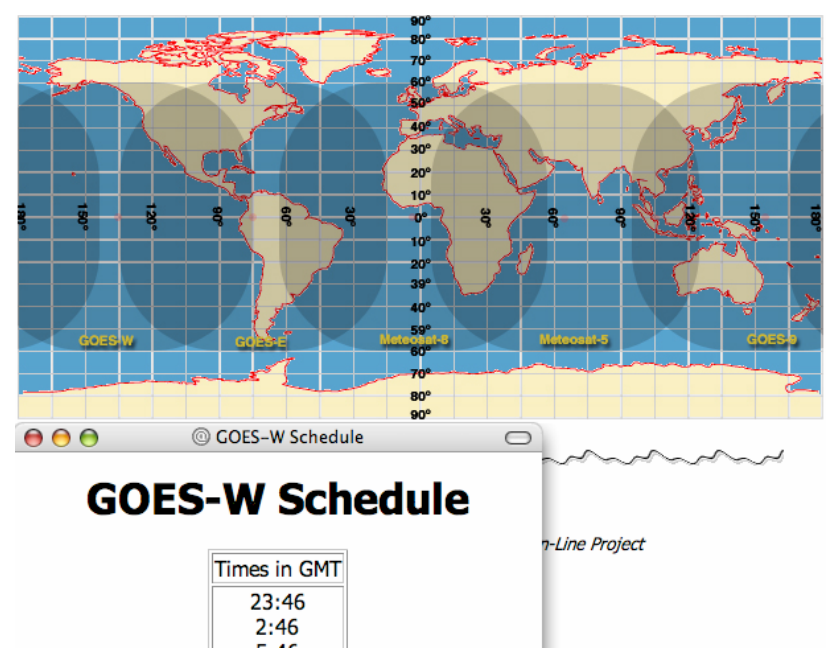

Fig. 3 Screen shot of clickable map for determination of 3-hourly geostationary observations times, with pop-up schedule for extreme southern Alaska 
A major focus of the S'COOL project is providing $\mathrm{K}-12$ teachers and students with up-to-date scientific information, written in an accessible manner. Over the years, the S'COOL website has grown to several hundred pages (many are translated into Spanish, French, German and Italian to facilitate participation both by other countries; and by English as a Second Language (ESL) and Bilingual Education students in the US. This addresses an early team finding that at some schools ESL students are taken out of science classes for additional English instruction, and thus were getting no science instruction). The S'COOL site includes basic information about the process of cloud observation and specific "how to" information for S'COOL, but also includes accessible discussions about the connection of clouds to larger issues such as the radiation budget. There are explanations of remote sensing, with examples that are specific to the topics that CERES is trying to address. There is also an extensive section of Teacher Resources where materials specifically designed for S'COOL are available; and links to related information on other websites are also listed. The links that are included are subject both to relevance and to suitability for the S'COOL audience.

Another mechanism that is used to bring real, current science into the classroom is the quarterly newsletter, the S'COOL Breeze. The format of this newsletter has evolved over the years. Each issue now contains 1-2 articles written by scientists for the S'COOL audience on timely topics. Recent examples include new developments in understanding effects of contrails on climate, use of the Moon as a calibration target for CERES, atmospheric science on Mars, etc. They also contain news on any recent S'COOL developments, such as the announcement of additional geostationary observing times. The remainder of the newsletter is specifically teacheroriented, with reviews of available lesson plans, useful websites, and other teaching resources.

Another way that S'COOL participants can gain current science knowledge is by submitting a question along with their observation report. These questions have been coming in at the rate of 6-12 per month, and are usually given a direct answer in a relatively short time. These questions also feed a
Frequently Asked Questions database which is available on the website for others to explore. Many of the questions that come in are quite simple, but a number of them reflect a high level of scientific thought on the part of the S'COOL participants.

\section{DISCUSSION}

The S'COOL Project was originally developed as a simple concept to obtain useful data for CERES validation. The S'COOL team attributes its success both to this simplicity, and to the connection with a real-world scientific study and need. We look forward to continuing to refine and expand the impact of S'COOL on science education for several years to come.

\section{ACKNOWLEDGMENT}

Funding for S'COOL is provided by NASA's Earth Science Enterprise. We also wish to recognize the CERES team for their willingness to encourage collaboration between the scientific and educational communities.

\section{REFERENCES}

[1] L.H. Chambers, D.F. Young, P.K. Costulis, P.T. Detweiler, J.D. Fischer, R. Sepulveda, D.B. Stoddard and A. Falcone, "The CERES S'COOL Project,” Bulletin of the American Meteorological Society, vol. 84 num.6, pp. 759-765, June 2003.

[2] Mace, G. G., Y. Zhang, S. Platnick, M. D. King, P. Minnis, and P. Yang, 2004: Evaluation of cirrus cloud properties from MODIS radiances using cloud properties derived from ground-based data collected at the ARM SGP site. Accepted, J. Appl. Meteorol.

[3[ National Aeronautics and Space Admin. Earth Science Enterprise Strategy, http://earth.nasa.gov/visions/ESE_Strategy2003.pdf, 2003.

[4] Uttal, T., S. Sun-Mack, P. Minnis, and J. Key, 2003: Comparison of surface and satellite measurements of Arctic cloud properties. Proc. 7th AMS Conf. Polar Meteorology and Oceanography, Hyannis, MA, 7-10 May, CD-ROM, 7.3.

[5] Wielicki, B. A., B. R. Barkstrom, E. F. Harrison, R. B. Lee III, G. L. Smith, and J. E. Cooper, 1996: "Clouds and the Earth's Radiant Energy System (CERES): An Earth Observing System Experiment," Bull. Amer. Meteor. Soc., 77, 853-868. 